\title{
Traditional Ecological Knowledge in Climate Change Adaptation: A review
}

\author{
Nadzirah Hosen 1, Hitoshi Nakamura ${ }^{2}$ \\ 1 Graduate School of Engineering and Science, \\ 2 Department of Planning, Architecture and Environmental Systems, \\ Shibaura Institute of Technology, Japan \\ na17506@shibaura-it.ac.jp, nakamu-h@shibaura-it.ac.jp
}

\begin{abstract}
Climate change puts indigenous people at greater risk than others. Nevertheless, because of their intimate knowledge of their land, indigenous peoples' traditional ecological knowledge (TEK) could be the answer to fighting climate change. This paper aims to explain the role that TEK plays in responding to climate change. Document analysis included grey literature as well as peer-reviewed literature and project websites linked to indigenous climate change adaptation knowledge. The findings show that TEK not only helps indigenous people cope with environmental and climate pressures, but also promotes socio-ecological system resilience.
\end{abstract}

Keywords: climate change adaptation; traditional knowledge; traditional ecological knowledge; resilience

elSSN 2398-4295 @2020. The Authors. Published for AMER ABRA cE-Bs by e-International Publishing House, Ltd., UK. This is an open access article under the CC BY-NC-ND license (http://creativecommons.org/licenses/by-nc-nd/4.0/). Peer-review under responsibility of Association of Malaysian Environment-Behaviour Researchers (AMER); Association of Behavioural Researchers on Asians / Africans / Arabians (ABRA); Centre for Environment-Behaviour Studies (cE-Bs), Faculty of Architecture, Planning \& Surveying, Universiti Teknologi MARA, Malaysia DOI: https://doi.org/10.21834/ajbes.v5i19.193 


\subsection{Introduction}

In the last few decades, the world has experienced rapid warming, with record high temperatures in the previous decade alone (Scripps Institution of Oceanography, 2017). The current pattern of warming is the result of human activities dating from the late 19th century. Ninety-seven per cent of climate scientists believe that human activities have led to climate change by burning fossil fuels (such as gas, oil, and coal) and other human drivers (Cook 2016). As a result, massive quantities of greenhouse gases were released into the atmosphere, thus raising the risk of intense and extreme hurricanes, floods, heatwaves, and droughts (IPCC, 2014a). Essentially, many scholars have believed climate change is the most complex environmental threat ever faced by this generation. With climate change impacting every corner of the globe, no one can avoid its impacts. Ironically, Indigenous people who follow a 'low-carbon' lifestyle are among the first communities who have been directly impacted by climate change.

Globally, climate change has put Indigenous people's homes and cultures at risk. It also intensified common problems (e.g., land and resource loss) as well as marginalised policies and economies, inequality, and unemployment. Nonetheless, given the challenges they face, Indigenous people have shown innovative and inventive ways to respond to changes in the environment (Nakashima et al. 2012). It is a direct product of their multi-generational experience and mutual understanding of land, sky, and sea, making them excellent climate-change observers and interpreters (Raygorodetsky, 2011; Wildcat, 2014). Such groups have traditionally faced numerous environmental hazards, resource shortages, and severe weather exposure (Byg \& Salick, 2009). Nevertheless, as always, Indigenous people make thorough observations of their natural climate, exchange perspectives, and prepare for the future (Hosen et al., 2019; Hosen et al., 2020). Their close relationship with nature makes them more sensitive to seasonal rhythms. Therefore, it helps them to cope with any changes based on centuries-old experience (McLean, 2012) or traditional ecological knowledge (TEK). TEK is the source of resilience for indigenous people, i.e., their capacity to adjust to environmental change based on a detailed understanding of the land (Scaddan, 2008). Essentially, TEK is an essential way of knowing, which can lead to climate change assessment and local response-based adaptation efforts. However, TEK remains one of the least understood components of recent climate change adaptation initiatives given its importance (Nalau et al., 2018). Many earlier research addressed TEK in natural resource management and conservation (e.g., Berkes, 2017; Popp et al., 2019). This paper aims at examining the role of the TEK in helping indigenous peoples adapt to climate change. Consequently the objectives of this paper are:

1. To analyse TEK's role in climate change adaptation based on TEK typologies

2. To develop a conceptual framework outlining TEK's role in adaptation to climate change and how it contributes to socio-ecological resilience

\subsection{Methodology}

The research methodology has three main steps:

1. Searching: A keyword-based analysis of grey literature, peer-reviewed literature, and project websites was conducted. Search keywords include TEK, climate change 
adaptation, climate change, traditional knowledge, Indigenous adaptation, Indigenous people, adaptive capacity, and resilience.

2. Screening: Related papers were screened using the following criteria: (1) the effect of climate change on indigenous peoples; and (2) local strategies to cope with climate change.

3. Examining: The related articles were examined to define TEK, TEK elements, the role of each component in climate change adaptation, and, finally, how TEK contributes to socio-ecological resilience.

As for research limitations, this paper focuses primarily on the social and environmental implications of climate change. The economic dimension does not fall within reach of this study

\subsection{Literature Review}

\subsection{Definition of TEK}

Different cultures around the world hold varying unscientific views of the natural world. Perhaps these 'other ways of knowing' are embedded in Indigenous people's traditional belief systems. Such knowledge provides sophisticated information that allows communities to interact with the natural world and cope with changes in the environment (Nakashima et al., 2012). Indigenous people regard their control of the environment as a critical part of their cultural heritage and social integrity (Mazzocchi, 2006). Many authors use various terminologies to define the knowledge system of the Indigenous community, such as Indigenous Knowledge (IK), Traditional Knowledge, and TEK. These words, however, bear slightly different meanings, although they sound very similar. For example, Magni (2016) identified IK as the local knowledge of Indigenous people or other unique cultural groups. In development literature, this concept is generally used to describe local ways of knowing as opposed to modern understanding of globalised culture or developmental science (Dudgeon \& Berkes, 2003). Dudgeon and Berkes (2003) also proposed that 'traditional knowledge' may be used as an alternative to IK. The term 'tradition' refers to cultural features, practices, or systems of thought imparted and thus retained from generation to generation (Graburn 2001). Tradition is not static in this sense, but cumulative, and open to change (Nicholas-Figueroa, 2017). In other words, a cultural community can respond to such change as their surroundings shift. TEK, on the other hand, was described as 'a cumulative body of knowledge, practice, and belief, evolving through adaptive processes and transmitted through generations through cultural transmission, about the relationship between living beings (including humans) and their environment' (Berkes, 1993: 4). Thus, within the larger body of IK literature, TEK is a 'more specific' subset.

Although both IK and TEK emphasise the social dynamics of relationships within a cultural community and the environment, TEK adds an ecological element; that is, it focuses on the dynamics of human-nature interaction, and local ways of understanding and communicating with the ecosystem (Dudgeon \& Berkes, 2003). This holistic approach stems from the very concept of ecology, that is, the connection between living organisms and their biophysical environment (Friederichs, 1958). Therefore, any component of the local biosphere, including plants, animals, 
and landforms, can be considered a part of the group and are treated with reverence and honour (Pierotti \& Wildcat, 2000). This knowledge base typically includes languages, naming and classification structures, sustainable resource use methods, traditions, indigenous worldviews, and spirituality (Boven \& Morohashi, 2002; Vinyeta \& Lynn, 2013). TEK is cumulative, dynamic, and adaptive. Indigenous people claim that TEK is not just knowledge of life, but their way of life (McGregor, 2004). As a self-management system, TEK is an instrument that helps indigenous peoples maintain and secure their way of life.

\subsection{Role of TEK in climate change adaptation}

Climate change adaptation has been an understated problem in recent decades, as mitigation seems more critical (Farber, 2007). Nonetheless, for any mitigating steps that take place, the consequences of climate change are inevitable, resulting in a growing need for adaptation. More significantly, climate change has brought about significant changes to the environment worldwide and requires multi-level adaptation strategies (i.e., global, national, and local) (Kettle \& Dow, 2014). In this regard, indigenous peoples have acquired unique knowledge, practices, and beliefs that bind them to the environment, making them a potentially significant contributor to robust climate adaptation action. TEK offers useful insights by presenting site-specific accuracy and complementary knowledge to scientific data (Vinyeta \& Lynn, 2013). In particular, local definitions of observed climate change are often more nuanced and holistic relative to the conventional climate model, which focuses solely on anthropogenic greenhouse gas emissions (Salick \& Byg, 2007). Detecting changes in the environment and designing strategies to adapt to those changes are necessary climate actions that TEK can inform (Parrotta \& Agnoletti, 2012).

In essence, TEK helps Indigenous people monitor changes in their local environment through TEK-based observations, and then record their adaptation strategies in response to those changes. Those abilities are rooted in the typologies of TEK. TEK consists of several interrelated empirical levels representing TEK's importance as a knowledge-practice-belief complex (Berkes, 1999, 2017; Houde, 2007; McMillen et al., 2014). The first level is an empirical observation, followed by second stage management strategies, third stage social organisation. Finally, the fourth stage underpins the first three levels of TEK, which shape perceptions regulating relationships between humans and the environment (Berkes, 2017).

Berkes (2017) and other scholars (e.g. Davidson-Hunt \& Berkes, 2003; Orlove \& Brush, 1996) have studied the TEK framework from the perspective of ecology, conservation of biodiversity, and management of natural resources. It deals with folk taxonomies, ethnobotanical and ethnozoological classifications of plants and animals, understanding of ecological processes including human relationships to animals, plants and sometimes supernatural influences (Berkes, 2017). This information is usually used to target species and develop methods to protect habitats and natural resources. This study, on the other hand, seeks to bring TEK to another level and address it from a different perspective, i.e., climate change. Table 1 compares the TEK perspective in this study with previous studies.

Table 1: Comparison of perspectives on TEK framework

TEK elements
Previous studies by Berkes

(2017) and others
This study 
Local knowledge of lands, animals

Resource management Species management systems

Social institutions

Worldviews
Species identification

Social institution for management of species

Values that shape the management of species across generations
Forecast and track surrounding changes (e.g., weather, climate, seasons, etc.) including phenology of plant and animal species

Land and resources management to adjust to changes/disturbance

Social relationship/ties, institutions, and behaviour of the communities that foster social cohesion in the face of changes/disturbance

Values that shape the management of land and resources, social relationship and behaviour; and accumulation of values across generations.

(Source: Author, 2020)

This research classifies TEK as (1) local knowledge of the environment, (2) land and resource management systems, (3) social networks and institutions, and (4) worldview and belief systems. Discussions are as follows.

\subsubsection{Local knowledge of the environment}

It includes the knowledge of the landscapes, soil, flora, and fauna, as well as classification, behaviour, and distribution (Berkes, 2017; Houde, 2007; McMillen et al., 2017). This form of knowledge also involves understanding the nature of the ecosystems, the interactions between animals and plants within it, and the role of biophysical parameters in influencing the behaviour of the entire population (Freeman, 1992). Inherently, indigenous people are capable of predicting the environment based on their knowledge of wind speed, sky coverage, animal behaviour, and length of precipitation (Garay-Barayazarra \& Puri, 2011). The Miriwoong tribe in East Kimberley, Australia, for example, observed the flowers on the Woolegalegeng (silver leaf paperbark tree) to anticipate thunderstorm arrival (Leonard et al., 2013). In the case of Kenyah Badeng farmers from Borneo Island, the behaviour of animals such as chickens and frogs, for example, their noise, are indicators of coming rains (Garay-Barayazarra \& Puri, 2011).

Seasonal shifts or cycles may also be observed, based on flora and fauna growth and reproduction. For instance, the harvest seasons for certain plants are indicated by the presence of certain insects, bird songs, or flowers. These phenological phenomena, i.e., weather and seasonal cycles, are critical to indigenous peoples due to their relation to the timing of their livelihood activities such as farming, hunting, fishing, and gathering. In order to live, indigenous people must be aware of even the slightest changes in their climate and must seek to adapt to those changes. For example, the Miriwoong people know that the Gali-Galing (Fern-leaf grevillea) flowering signals the beginning of the cold season, and therefore, as a reaction to this natural event, they begin their traditional burning practices. Indeed, many indigenous groups have a traditional calendar for scheduling their seasonal activities (e.g., Garay-Barayazarra \& Puri, 2011; Leonard et al., 2013; Prober et al., 2011). This local knowledge will usually bring some fundamental insights into research into climate change. Although experimental climate models forecast large-scale environmental changes (i.e., melting of snow and ice, sea-level rise, high 
water temperature, etc.), local non-industrial population observations provide information on smaller, more practical scales.

Besides, Indigenous people's inherent knowledge of the environment allows these groups to predict changing circumstances and situations that could present significant risks. Observations and approaches to resolve changes in socio-ecological processes are significant assets that could guide planning for climate change adaptation. They may help explain changes, effects on local communities and their environments, and coping strategies to respond to those impacts.

\subsubsection{Land and resource management}

Land and resource management systems include the knowledge of indigenous people about the use of natural resources, as well as land and marine management techniques that have developed through adaptive processes (Leonard et al., 2013; McMillen et al., 2014). Possession of these systems helps indigenous communities to plan for anticipated risk through a sustainable adjustment of practices and the implementation of suitable technologies. In the climate change context, land and resource management systems are crucial for building adaptive capacity that contributes to community resilience (McMillen et al., 2014; McMillen et al., 2017). In some cases, indigenous people make an adaptive decision to ration resources, which corresponds to ecological productivity to avoid food depletion. This reaction will, therefore, allow the regeneration of surrounding ecosystems (Berkes et al., 2000; Gómez-Baggethun et al., 2012; Ingty, 2017; McMillen et al., 2014).

Besides, indigenous management systems also promote diversification, which helps to spread risks across spatiotemporal scales by providing a range of options, thereby increasing resilience during shocks (Agrawal, 2008). Examples include swidden agriculture, integrated farming, agroforestry, farming, and crop varieties (Berkes et al., 2000; Hobson, 1992; Magni, 2016). Such a combination and selection of different livestock and crop varieties in an integrated farming system encourages bio-cultural diversity, which is not only resilient to climate change but also has high rates of carbon sequestration in the fight against change (Singh et al., 2011). Another approach is mobility, reducing spatial risks (Agrawal \& Perrin, 2008). For example, one of the oldest systems still practiced by indigenous peoples is crop shifting, i.e., the communities left the cropland uncultivated to preserve fertility for a certain period of time (Hillel, 2005). Land fertility encourages crop production and surplus yields. Lastly, resource storage minimises risks over time, especially in reducing food shortages (Agrawal \& Perrin, 2008; Gómez-Baggethun et al., 2012). Indigenous communities in Asia, for example, have developed food preservation and storage practices, such as using physical structures to store crops and water, and drying food when food is abundant (AIPP, 2012)

\subsubsection{Social networks and institutions}

Social networks and institutions are social structures of TEK that define the social behaviour of group members when faced with disturbance. Such systems have a significant impact on indigenous survival and adaptation. In the context of climate change, social networks and institutions foster adaptive capacity within social-ecological systems by buffering up disruptions, encouraging self-organisation, and fostering social learning (McMillen et al., 2014). For instance, 
Ka'ūpūlehu indigenous people in Hawaii and Dõnana, Spain, have both practiced community pooling in challenging times. Such pooling includes the sharing of assets and services (such as food, natural resources, human resources, and infrastructure) among households during shortages on a mutual basis (Agrawal \& Perrin, 2008; Gómez-Baggethun et al., 2012). As a result, these tribes were able to increase the abundance of food and resources and diversity over time and space, which gave them a buffer against difficulties, particularly when resources were limited, e.g., during a tsunami, drought, and other disturbances (McMillen et al., 2017).

In addition, local leadership and institutions promote self-organisation which provides the ability to react to shocks. Strong local leadership and institutions may encourage efficient allocation systems, foster sustainability, create community social cohesion and store collective memory (Brown \& Sonwa, 2015; Gómez-Baggethun et al., 2012; Ingty, 2017). For example, among alpine Himalayan tribes, the traditional institution, namely the Dzumsa, which is made up of 12 Lachen valley village members, is very responsive to environmental stresses. Such institution has been instrumental in preventing resource overuse, preserving resource reserves, and providing social, ecological, and economic stability through resource partitioning (Ingty, 2017). Generally, social institutions and networks based on reciprocity and trust can impact group resilience. The strengthening of existing social systems and networks is essential in the context of climate change adaptation planning. It allows efficient distribution and facilitation of resource and information exchange required to deal with disruptions (McMillen et al., 2014).

\subsubsection{Worldview and belief systems}

Worldview and belief systems of indigenous peoples underpin the first three elements of TEK, thereby playing crucial roles within TEK as a whole. These systems are the basis on which local knowledge and resource management practices, as well as social networks and organisations, are developed and transmitted. Often this transmission takes the form of myths, taboos, tales, ceremonies and rituals, and other associated cultural practices. In other words, worldview and belief systems are a mechanism for transmitting knowledge between generations within a context embedded in social systems (Berkes et al., 2000: 1257). For example, the milpa script (related to the milpa agroforestry system) passed from generation to generation and maintained by mythologies, cultural beliefs, and annual festivals (Folke \& Berkes, 1998). In practice, these traditions help to create strong social networks and maintain reciprocal ties by exchanging and sharing knowledge and resources. By building trust and creating a bond between community members, they will create and cultivate healthy and lasting relationships between the individuals (Ziegler, 2007).

Consequently, individuals may rely on these reciprocity relationships during tough times, thereby helping to ensure the resilience of resource access. The Kula Ring is an example of a ceremonial exchange of gifts made from shells in Papua New Guinea (McMillen et al., 2014). Worldviews of indigenous peoples also include cultural and spiritual values that promote cooperation, reciprocity, and respect, which are necessary for TEK to work. Such values are, in turn, the key factors sustaining traditional traditions and systems (Swiderska et al., 2011). In general, the worldview of indigenous peoples is crucial to preserving the continuity of TEK, 
particularly in the globalised world. The loss of TEK means the loss of alternative ways of adapting to changes in the environment, particularly in the face of climate change.

\subsection{Findings \& Discussion}

Following the search, screening, and review of relevant articles, several adaptation approaches were developed based on TEK's major components. These components include forecasting, rationing, diversification, mobility, storage, and pooling. Interestingly, most adaptation practices follow the classification of local adaptation given by Agrawal (2008), Prasad et al. (2009), and Gómez-Baggethun et al. (2012). Such practices are important for the promotion of resilience, which plays a role in social and ecological processes that sustain the well-being of the socialecological system. Table 2 demonstrates how all of these components interrelate and contribute to socio-ecological resilience.

Table 2: TEK, adaptation strategies, and resilience

\begin{tabular}{|c|c|c|c|c|}
\hline $\begin{array}{c}\text { Elements of } \\
\text { TEK }\end{array}$ & \multicolumn{2}{|c|}{ Adaptation Strategies } & \multicolumn{2}{|c|}{ Resilient Attributes } \\
\hline $\begin{array}{l}\text { Local } \\
\text { knowledge of } \\
\text { the } \\
\text { environment }\end{array}$ & Forecasting & $\begin{array}{l}\text { Local observation helps } \\
\text { develop strategies to cope } \\
\text { and adapt }\end{array}$ & \multirow{5}{*}{$\begin{array}{l}\text { Ecological } \\
\text { diversity } \\
\text { Ecosystem } \\
\text { services }\end{array}$} & \multirow{5}{*}{$\begin{array}{l}\text { The protection and } \\
\text { enhancement of } \\
\text { natural ecosystems } \\
\text { and biodiversity will } \\
\text { enhance resilience. } \\
\text { Diverse ecosystem } \\
\text { recovers rapidly as } \\
\text { they have more } \\
\text { options to cope with } \\
\text { different forms of } \\
\text { disturbance } \\
\text { (Dunn \& Velez, 2018) }\end{array}$} \\
\hline \multirow[t]{4}{*}{$\begin{array}{l}\text { Land and } \\
\text { resource } \\
\text { management }\end{array}$} & Rationing & $\begin{array}{l}\text { Temporal restriction of } \\
\text { harvest in response to } \\
\text { common shortages allow } \\
\text { the renewal of surrounding } \\
\text { ecosystems }\end{array}$ & & \\
\hline & Diversification & $\begin{array}{l}\text { A mixture and selection of } \\
\text { various livestock, crop } \\
\text { varieties, and other } \\
\text { resources promotes } \\
\text { biocultural diversity }\end{array}$ & & \\
\hline & Mobility & $\begin{array}{l}\text { A land which has been left } \\
\text { for years to rest } \\
\text { encourages the } \\
\text { regeneration of vegetation }\end{array}$ & & \\
\hline & Storage & $\begin{array}{l}\text { Stockpiling emergency food } \\
\text { supplies contribute to food } \\
\text { security and creates a } \\
\text { resilient food system }\end{array}$ & & \\
\hline $\begin{array}{l}\text { Social } \\
\text { networks and } \\
\text { institutions }\end{array}$ & Pooling & $\begin{array}{l}\text { Community share assets } \\
\text { and resources (e.g., food, } \\
\text { natural resources, labour, } \\
\text { and infrastructure) across } \\
\text { households on a reciprocity } \\
\text { basis. Local leadership and } \\
\text { institutions build social } \\
\text { cohesion within the } \\
\text { community }\end{array}$ & $\begin{array}{c}\text { Social capital \& } \\
\text { self- } \\
\text { organisation }\end{array}$ & $\begin{array}{l}\text { Social capital } \\
\text { comprising qualities } \\
\text { such as collective } \\
\text { action, reciprocity, } \\
\text { and participation is an } \\
\text { asset for resilience } \\
\text { (Ledogar \& Fleming, } \\
\text { 2008) }\end{array}$ \\
\hline
\end{tabular}




\begin{tabular}{l|l|l|l|l}
\hline $\begin{array}{l}\text { Worldviews } \\
\text { and belief } \\
\text { systems }\end{array}$ & $\begin{array}{l}\text { Knowledge \& } \\
\text { cultural } \\
\text { transmission }\end{array}$ & $\begin{array}{l}\text { Transmitting knowledge } \\
\text { and values across } \\
\text { generations promote } \\
\text { collective long-term } \\
\text { memory of adaptations }\end{array}$ & $\begin{array}{l}\text { The ability to learn } \\
\text { and share information } \\
\text { learning }\end{array}$ & $\begin{array}{l}\text { from past experiences } \\
\text { is key to resilience } \\
\text { (Duchek, 2019) }\end{array}$ \\
\hline
\end{tabular}

(Source: Author, 2020)

Based on the TEK components, a conceptual framework is built that bridges TEK, climate change adaptation, and socio-ecological resilience, as shown in Fig. 1.

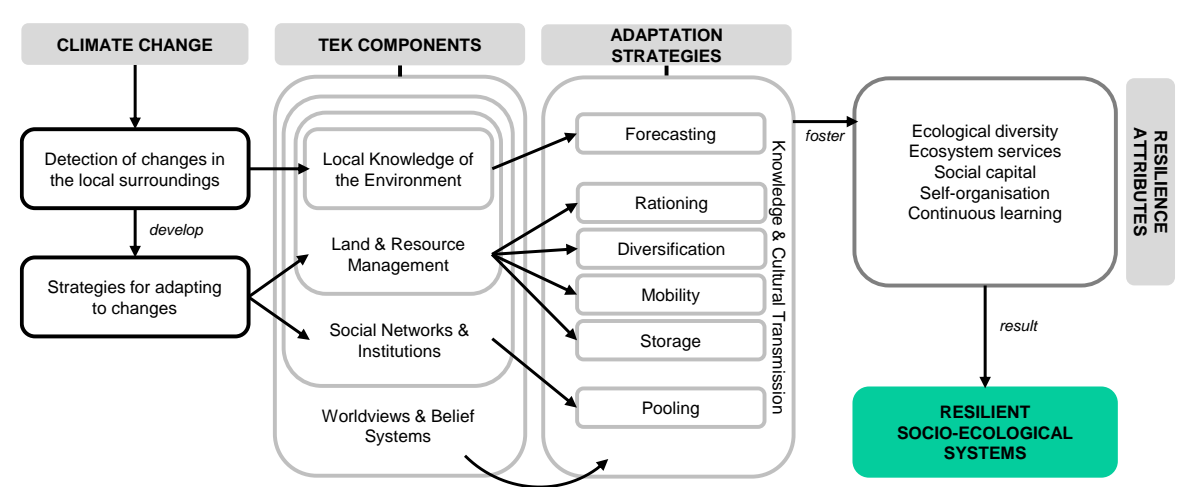

Fig. 1: Bridging TEK, adaptation, and resilience of socio-ecological systems (Source: Author, 2020)

Socio-ecological systems involve the complex interactions between humans and the biophysical environment, which has increasingly been recognised as a method for conceptualising human-environmental processes and how they can be managed to be resilient. (Berkes et al., 2003; Stokols et al., 2013). In the context of social-ecological systems, resilience denotes the following: (1) The ability of a system to retain its identity, structure, and feedback after encountering a set of change (Walker et al., 2004), and (2) the ability of the system to reconstruct after it has crossed a threshold (Folke, 2016). Importantly, these abilities are distinguished by several attributes: (1) ecological diversity; (2) ecosystem services; (3) social capital inclusive of social connections and participation in community groups; (4) self-organisation; and (5) continuous learning in response to environmental change (Folke et al., 2002; Gómez-Baggethun et al., 2012; Walker \& Salt, 2006). As stated, the development of these attributes has been substantially promoted by adaptation activities rooted in TEK.

\subsection{Conclusion \& Recommendations}

Overall, this paper has met the objectives proposed at the beginning of the study. TEK, which comprises the local knowledge of the environment; land and resource management; social networks and institutions; and worldviews and belief systems, help Indigenous communities define climate change and develop local-specific adaptation strategies. More specifically, these 
strategies are crucial to promoting the resilience of the socio-ecological system. Under uncertain conditions, they improve society's capacity to cope with change and sustain ecosystems, as the knowledge base coexists with socio-ecological systems. The framework is therefore useful for guiding place-based research involving TEK in climate change studies since each part of TEK within the structure has its role to consider. Future study, however, needs to provide concrete evidence to support the conceptual structure outlined in this paper.

\section{References}

Agrawal, A. (2008). The Role of Local Institutions in Adaptation to Climate Change. Washington D. C, USA: World Bank. Agrawal, A., \& Perrin, N. (2008). Climate adaptation, Local Institutions and Rural Livelihoods. In IFRI Working Paper (Vols. W081-6).

AIPP. (2012). Indigenous Peoples and Climate Change Adaptation in Asia. Chiang Mai: AIPP Printing Press.

Berkes, F. (1993). Traditional ecological knowledge in perspective. In J. T. Inglis (Ed.), Traditional Ecological Knowledge: Concepts and Cases (pp. 1-9). Canadian Museum of Nature and the International Development Research Centre.

Berkes, F. (1999). Sacred Ecology: Traditional Ecological Knowledge and Resource Management. Philadelphia, PA, USA: Taylor \& Francis.

Berkes, F. (2017). Sacred Ecology (Fourth). New York, NY, USA: Routledge.

Berkes, F., Colding, J., \& Folke, C. (2000). Rediscovery of Traditional Ecological Knowledge as Adaptive Management. Ecological Applications, 10(5), 1251-1262.

Boven, K., \& Morohashi, J. (2002). Best Practices using indigenous knowledge (K. Boven \& J. Morohashi (Eds.)). Nuffic, The Hague, The Netherlands, and UNESCO/MOST.

Brown, H. C. P., \& Sonwa, D. J. (2015). Rural local institutions and climate change adaptation in forest communities in Cameroon. Ecology and Society, 20(2).

Byg, A., \& Salick, J. (2009). Local perspectives on a global phenomenon-Climate change in Eastern Tibetan villages. Global Environmental Change, 19(2), 156-166.

Cook, J. (2016). Consensus on consensus: a synthesis of consensus estimates on human-caused global warming.

Davidson-Hunt, I., \& Berkes, F. (2003). Learning as you journey: Anishinaabe perception of social-ecological environments and adaptive learning. Ecology and Society, 8(1).

Duchek, S. (2019). Organizational resilience: a capability-based conceptualization. Business Research, 13(1), 215-246.

Dudgeon, R. C., \& Berkes, F. (2003). Local Understandings of the Land: Traditional Ecological Knowledge and Indigenous Knowledge. In H. Selin (Ed.), Nature Across Cultures: Views of Nature ami the Environment in Non-Western Cultures (pp. 75-96). Kluwer Academic Publishers.

Dunn, B., \& Velez, C. (2018). Managing the perfect storm: How healthy ecosystems increase resilience. Asian Development Bank. 
Farber, D. A. (2007). Adapting to climate change: Who should pay. Journal of Land Use, 23(1), 1-38.

Folke, C. (2016). Resilience (Republished). Ecology and Society, 21(4).

Folke, C., \& Berkes, F. (1998). Understanding Dynamics of Ecosystem Institution Linkages for Building Resilience.

Folke, C., Carpenter, S., Elmqvist, T., Gunderson, L., Holling, C., \& Walker, B. (2002). Resilience and Sustainable Development: Building Adaptive Capacity in a World of Transformations. Ambio, 31(5), 337-440.

Freeman, M. M. R. (1992). The Nature and Utility of Traditional Ecological Knowledge. Northern Perspectives, 20(1), 9$12 \mathrm{pp}$.

Friederichs, K. (1958). A Definition of Ecology and Some Thoughts About Basic Concepts. Ecology, 39(1), 154-159.

Garay-Barayazarra, G., \& Puri, R. K. (2011). Smelling the monsoon: Senses and traditional weather forecasting knowledge among the Kenyah Badeng farmers of Sarawak, Malaysia. Indian Journal of Traditional Knowledge, 10(1), 21-30.

Gómez-Baggethun, E., Reyes-García, V., Olsson, P., \& Montes, C. (2012). Traditional ecological knowledge and community resilience to environmental extremes: A case study in Doñana, SW Spain. Global Environmental Change, 22(3), 640-650.

Graburn, N. H. H. (2001). What is Tradition? Museum Anthropology, 24(2/3), 6-11.

Halim, A. A., Jawan, J. A., Ismail, S. R., Othman, N., \& Ibrahim, N. N. (2012). Indigenous Knowledge and Biodiversity Conservation in Sabah , Malaysia. International Journal of Social Science and Humanity, 2(2), 159-163.

Hillel, D. (Ed.). (2005). Encyclopedia of Soils in the Environment. Elsevier Ltd.

Hobson, G. (1992). Traditional Knowledge Is Science. ICSU.

Hosen, N., Nakamura, H., \& Hamzah, A. (2019). Traditional Ecological Knowledge and Climate Change Adaptation: The Sa'ban experience. Journal of ASIAN Behavioural Studies, 4(14).

Hosen, N., Nakamura, H., \& Hamzah, A. (2020). Adaptation to Climate Change : Does Traditional Ecological Knowledge Hold the Key? Sustainability, 12, 676.

Houde, N. (2007). The six faces of traditional ecological knowledge: Challenges and opportunities for Canadian comanagement arrangements. Ecology and Society, 12(2).

Ingty, T. (2017). High mountain communities and climate change: adaptation, traditional ecological knowledge, and institutions. Climatic Change, 145(1-2), 41-55.

IPCC. (2014a). Climate Change 2014: Synthesis Report. WMO and UNEP.

IPCC. (2014b). Glossary. In Intergovernmental Panel on Climate Change.

Kettle, N. P., \& Dow, K. (2014). Cross-level differences and similarities in coastal climate change adaptation planning. Environmental Science and Policy, 44, 279-290.

Ledogar, R. J., \& Fleming, J. (2008). Social Capital and Resilience: A Review of Concepts and Selected Literature Relevant to Aboriginal Youth Resilience Research. Pimatisiwin, 6(2), 25-46. 
Leonard, S., Parsons, M., Olawsky, K., \& Kofod, F. (2013). The role of culture and traditional knowledge in climate change adaptation: Insights from East Kimberley, Australia. Global Environmental Change, 23(3), 623-632.

Magni, G. (2016). Indigenous knowledge and implications for the sustainable development agenda (Global Education Monitoring Report).

Mazzocchi, F. (2006). Western science and traditional knowledge. EMBO Reports (European Molecular Biology Organization), 7(5), 463-466.

McGregor, D. (2004). Traditional ecological knowledge and sustainable development: towards co-existence. In M. Blaser, H. A. Feit, \& G. McRae (Eds.), In the Way of Development. Indigenous Peoples, Life Projects and Globalization (pp. $72-$ 91). London, UK; New York, NY, USA: Zed Books.

McLean, K. G. (2012). Land Use, Climate Change Adaptation and Indigenous Peoples - Our World. United Nations University.

McMillen, H. L., Ticktin, T., Friedlander, A., Jupiter, S. D., Thaman, R., Campbell, J., Veitayaki, J., Giambelluca, T., Nihmei, S., Rupeni, E., Apis-Overhoff, L., Aalbersberg, W., \& Orcherton, D. F. (2014). Small islands, valuable insights: Systems of customary resource use and resilience to climate change in the Pacific. Ecology and Society, 19(4).

McMillen, H., Ticktin, T., \& Springer, H. K. (2017). The future is behind us: traditional ecological knowledge and resilience over time on Hawai'i Island. Regional Environmental Change, 17(2), 579-592.

Nakashima, D.J., Galloway McLean, K., Thulstrup, H.D., Ramos Castillo, A. and Rubis, J. T. (2012). Weathering Uncertainty: Traditional Knowledge for Climate Change Assessment and Adaptation (D. McDonald (Ed.)). UNESCO and UNU-TKI.

Nalau, J., Becken, S., Schliephack, J., Parsons, M., Brown, C., \& Mackey, B. (2018). The role of indigenous and traditional knowledge in ecosystem-based adaptation: A review of the literature and case studies from the Pacific Islands. Weather, Climate, and Society, 10(4), 851-865.

Nicholas-Figueroa, L. (2017). Traditional Ecological Knowledge of Stem Concepts in Informal and Place-based Western Educational Systems: Lessons from The North Slope, Alaska. University of Alaska Fairbanks.

Orlove, B. S., \& Brush, S. B. (1996). Anthropology and the Conservation of Biodiversity. Annual Review of Anthropology, 25(1), 329-352.

Parrotta, J. A., \& Agnoletti, M. (2012). Traditional forest-related knowledge and climate change. In J. A. Parrotta \& R. L. Trosper (Eds.), Traditional forest-related knowledge: sustaining communities, ecosystems and biocultural diversity (pp. 491-534). Springer.

Pierotti, R., \& Wildcat, D. (2000). Traditional ecological knowledge: The third alternative (commentary). Ecological Applications, 10(5), 1333-1340.

Popp, J. N., Priadka, P., \& Kozmik, C. (2019). The rise of moose co-management and integration of Indigenous knowledge. Human Dimensions of Wildlife, 24(2), 159-167.

Prasad, N., Ranghieri, F., Shah, F., Trohanis, Z., Kessler, E., \& Sinha, R. (2009). Climate Resilient Cities: A Primer on Reducing Vulnerabilities to Disasters. The World Bank.

Prober, S. M., O'Connor, M. H., \& Walsh, F. J. (2011). Australian Aboriginal peoples' seasonal knowledge: A potential basis for shared understanding in environmental management. Ecology and Society, 16(2). 
Raygorodetsky, G. (2011). Why Traditional Knowledge Holds the Key to Climate Change. UNU-TKI.

Salick, J., \& Byg, A. (2007). Indigenous peoples and climate change. In Tyndall Center for Climate Change Research, University of Oxford and Missouri Botanical Garden (Vol. 32, Issue 2).

Scaddan, C. (2008). Climate change and indigenous peoples. In United Nations Permanent Forum on Indigenous Issues. New York, NY, USA: United Nations

Scripps Institution of Oceanography. (2017). The Keeling Curve. Scripps Institution of Oceanography. https://scripps.ucsd.edu/programs/keelingcurve/

Swiderska, K., Reid, H., Song, Y., Li, J., Mutta, D., Ongugo, P., Pakia, M., Oros, R., \& Barriga, S. (2011). The Role of Traditional Knowledge and Crop Varieties in Adaptation to Climate Change and Food Security in SW China, Bolivian Andes and coastal Kenya. In UNU-IAS workshop on Indigenous Peoples, Marginalised Populations and Climate Change: Vulnerability, Adaptation and Traditional Knowledge.

Vinyeta, K., \& Lynn, K. (2013). Exploring the Role of Traditional Ecological Knowledge in Climate Change Initiatives. Portland, Oregon, USA: U.S Department of Agriculture, Forest Service, Pacific Northwest Research Station.

Walker, B. H., \& Salt, D. (2006). Resilience thinking: sustaining ecosystems and people in a changing world. Washington D.C, USA: Island Press.

Walker, B., Holling, C. S., Carpenter, S. R., \& Kinzig, A. (2004). Orientation and dynamics of a vesicle in tank-treading motion in shear flow. Ecology \& Society, 9(2).

Wildcat, D. R. (2014). Introduction: climate change and indigenous peoples of the USA. In J. K. Maldonado, B. Colombi, \& R. Pandya (Eds.), Climate Change and Indigenous Peoples in the United States: Impacts, Experiences and Actions (pp. 1-7). Switzerland: Springer International Publishing.

Ziegler, R. (2007). The Kula Ring of Bronislaw Malinowski: A simulation model of the co-evolution of an economic and ceremonial exchange system (Vol. 2007). 